\title{
High-Molecular-Weight HPMA-Based Polymer Drug Carriers for Delivery to Tumor
}

\author{
L. $\operatorname{KOSTKA}^{1}$, T. ETRYCH ${ }^{1}$ \\ ${ }^{1}$ Institute of Macromolecular Chemistry of the Czech Academy of Sciences, Prague, Czech \\ Republic
}

Received July 14, 2016

Accepted July 14, 2016

\begin{abstract}
Summary
In this work, design and synthesis of high-molecular-weight $\mathrm{N}$-(2hydroxypropyl)methacrylamide-based polymer drug delivery systems tailored for cancer therapy is summarized. Moreover, the influence of their architecture on tumor accumulation and in vivo anti-cancer efficacy is discussed. Mainly, the high-molecularweight delivery systems, such as branched, grafted, multi-block, star-like or micellar systems, with molecular weights greater than the renal threshold are discussed and reviewed in detail.
\end{abstract}

\section{Key words}

Nanotherapeutics $\bullet \mathrm{pH}$ responsive $\bullet$ HPMA copolymers

\section{Corresponding author}

L. Kostka, Department of Biomedicinal Polymers, Institute of Macromolecular Chemistry of the Czech Academy of Sciences, Heyrovského nám. 2, 16206 Prague 6, Czech Republic. E-mail: kostka@imc.cas.cz

\section{Introduction}

Recently, there have been significant efforts to establish the field of nanomedicines and to develop nanocarriers for drug delivery and imaging. This boosted the development of nano-sized materials, such as polymers, micelles or nanoparticles, with the potential to serve as efficient diagnostic and/or therapeutic tools against severe diseases, including cancer, infectious and neurodegenerative disorders. Advanced polymer chemistry offers powerful tools for the development of new polymeric drugs. Novel polymer drug delivery systems (DDS) have been developed and tested in numerous preclinical and clinical studies. The design of new polymer-drug conjugates is based on the idea that synthetic polymer carriers (Duncan 2006, Pasut et al. 2008, Kopeček 2010) can enable passive and active tumor-specific drug delivery. The conjugation of a chemotherapeutic agent to a hydrophilic polymer carrier increases the solubility of water-insoluble drugs, prolongs the circulation of the polymer-drug conjugate in the blood, influences the pharmacokinetics and biodistribution of the drug, decreases the incidence of toxic side effects and reduces therapy-dependent cancer resistance, which was shown earlier for N-(2-hydroxypropyl)methacrylamide (HPMA) copolymers of various

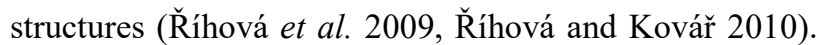
The Enhanced Permeability and Retention Effect (EPR) described by Maeda and Matsumura is based on the preferential accumulation of high-molecular-weight (HMW) polymer drug conjugates in solid tumors, and the efficiency of their accumulation is molecular weightdependent (Matsumura and Maeda 1986, Maeda et al. 2006). Furthermore, fluid-phase and receptor-mediated pinocytosis are the most important mechanisms underlining the subsequent uptake of water-soluble polymer drug conjugates by target tumor cells. The balance between the elimination of polymeric drugs from the bloodstream by the kidneys, liver and other organs and extravasation from the blood vasculature into the tumor influences the effectiveness of drug delivery (Fox et al. 2009). The structure of the glomerular capillary wall and the glomerular permeability of macromolecules have been described in several papers and reviews (Venkatachalam and Rennke 1978, Rennke and 
Venkatachalam 1979, Tencer et al. 1998, Deen et al. 2001, Asgeirsson et al. 2007, Asgeirsson et al. 2009). Macromolecular clearance decreases with increasing hydrodynamic radius ( $\mathrm{Rh}$ ) and molecular weight and is influenced by the charge of the polymer. The clearance of negatively charged macromolecules is restricted, while the clearance of positively charged macromolecules with the same molecular weight is enhanced (Rennke and Venkatachalam 1979, Lammers et al. 2005). The renal clearance of linear flexible macromolecules, such as dextran and poly(vinylpyrrolidone), is up to 10-times greater than that of proteins with equivalent hydrodynamic radii (Venkatachalam and Rennke 1978). Macromolecular branching leads to decreased renal clearance and significantly prolongs blood circulation time (Fox et al. 2009, Nasongkia et al. 2009).

\section{Polymer prodrug carriers}

Suitable nanosized materials based on polymers have been studied because of the broad diversity of the properties, composition and architecture of polymers. The first and simplest method to incorporate drugs into these nano-carriers is drug encapsulation during the selfassembly of amphiphilic copolymers in aqueous solutions or into hydrophobic matrix. Despite very promising results, these drug delivery systems face strong limitations that may obstruct their further transfer into use in clinical trials and subsequently to the market: (i) the "burst effect (release)", during which a large fraction of adsorbed drug is spontaneously released after administration, can lead to severe toxicity in vivo; (ii) the encapsulation of drugs with poor solubility that have a tendency to crystallize often requires the use of additional organic co-solvents during nanomedicine preparation; and (iii) poor and insufficient drug loading, generally only a few percent, usually requires a relatively high concentration of the polymer carrier to obtain a noticeable therapeutic effect, which can be toxic and damaging to patients itself. The most favorable approach seems to be a prodrug approach, in which the drug is covalently linked to an appropriate polymer carrier (Kopeček's model on Fig. 1). The inactive prodrug is further metabolized in vivo into an active drug or its metabolite. In the case of polymer prodrugs, this strategy improves drug solubility, prolongs circulation in the blood, positively changes the pharmacokinetics and pharmacodynamics of the drug and reduces adverse side effects. The reduction in side effects is a majorly important feature for many chemotherapy treatments and can influence the therapy outcome via immune system damage. Furthermore, the materials used for the construction of drug carriers must be nontoxic, biocompatible, non-immunogenic and must be cleared from the body to prevent long-term accumulation of the carrier in the organism.

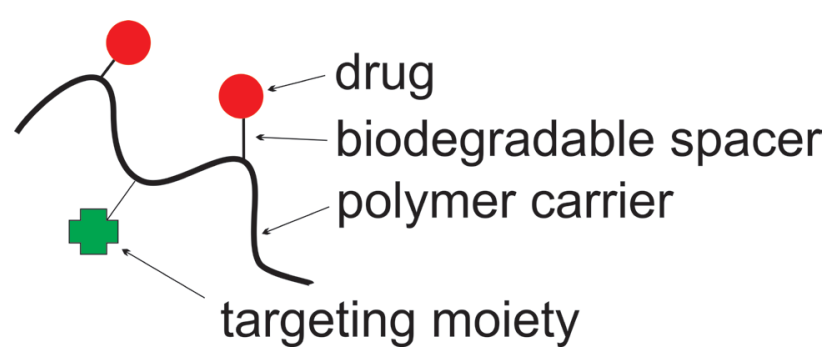

Fig. 1. Schematic description of Kopeček's model of polymer prodrugs (Kopeček 1981) based on the simplified Helmut Ringsdorf's model.

Many polymer prodrug carrier systems have been proposed and tested as DDS during the last decades. Many of these systems are based on water-soluble polymer carriers bearing low-molecular-weight drugs; e.g. cytostatic agents covalently bound to biodegradable spacers that release the drug in its active form in tumor tissues or cells in a controlled manner. The development of polymer science enabled the synthesis of novel polymer carriers with tailored-made structures and appropriate functional groups for attachment of drugs or other biologically active compounds. To avoid the unwanted accumulation of carriers in the organism, synthetically prepared polymer carriers should be eliminated from the organism after delivering their cargo into the target cells or tissue. Thus, they can be divided into two subgroups according to the biodegradability of the polymer backbone, polymers with biodegradable backbones and not biodegradable polymers. Biodegradable polymer carriers are degraded into small fragments, which are further metabolized or removed by renal filtration in a similar manner as low-molecularweight compounds. Poly( $\alpha$-amino acids); e.g. poly(LLysine), poly(L-aspartic acid), poly(L-glutamic acid) (PGA) and their derivatives, which are polymer carriers that are degradable by enzymatic activity in the body, are an example of these carriers (Schacht et al. 1996, Li 2002). They can be prepared by anionic ring-opening polymerization of their respective $\mathrm{N}$-carboxyanhydrides (NCAs). For example, a conjugate of PGA with the 
anticancer drug paclitaxel (Ptx) is under clinical investigation (Phase II/III) (Duncan and Vicent 2013). In this case, Ptx is bound to the polymer carrier by an ester bond that is susceptible to lysosomal protease degradation, leading to the release of a diglutamate derivative of Ptx and consecutively, free Ptx. In general, charged polymers, like poly( $\alpha$-amino acid)s, have some disadvantages, such as undesired interactions with the compartments of the body and their unspecific accumulation in organs, e.g. liver or kidney. However, in some cases, such limitations can be utilized for the specific and advantageous targeting of these tissues. For example, the conjugate with Ptx mentioned above and investigated in clinical trials is intended for the treatment of ovarian cancer because of the enhanced accumulation of the conjugate in the ovaries that is driven by the structure of polymer carrier.

Another examples of biodegradable polymers are polymers, whose fundamental blocks with molecular weight below renal threshold are connected with biodegradable linkages (Pechar et al. 2005). pH sensitive, enzymatically or reductively degradable linkers can be utilized in the synthesis.

The polymer backbones of a majority of synthetic polymer carriers are not biodegradable. To prevent the undesired accumulation of carriers in the body, which can lead to serious long-term side effects, the molecular weight of polymer carriers must be below the renal threshold to ensure safe elimination of the carriers after fulfilling their role.

Otherwise, polymer carriers should be removed by the hepatobiliary system, but this is a very slow process. The second choice is not optional due to the very long circulation time of polymer in the body (several weeks). The most studied non-degradable water soluble polymer used for the synthesis of polymer-drug conjugates is polyethylene glycol (PEG) (Pasut and Veronese 2009). The drawback of PEG carriers is that a limited number of groups on PEG are appropriate for the attachment of drugs; only polymer chain ends can be used. The drug payload can be increased by adding branched, dendron or fork-like structures to the end chain group. Recently, poly(2-oxazoline) polymers (POx) have been proposed as an alternative to PEG (Viegas et al. 2011). It is possible to adjust their properties, such as, hydrophobicity, using different monomers during synthesis. Their synthesis enables the introduction of desired functional groups along the polymer backbone.

Barring PEG, the vast majority of synthetic polymer carriers with non-degradable polymer backbones are water-soluble vinyl-based polymers and copolymers. In the past, they were usually prepared by free radical polymerization; however, in last decade, the number of polymers synthesized by controlled radical polymerization, such as atom transfer radical polymerization (ATRP) or reversible addition fragmentation chain transfer (RAFT) polymerization, is rapidly growing. A wide range of available monomers enables the synthesis of tailored-made polymer carriers containing suitable functional groups for the attachment of the selected biologically active compounds (Schacht et al. 1996). Numerous polymer carriers and their drug conjugates have been proposed; including poly(divinylether-co-maleinanhydride), poly(styren-altmono-n-butylmaleinate), poly(1-vinyl-2-pyrrolidone), poly(1-vinyl-2-pyrrolidone-co-maleinanhydride),

poly[(N-acryloyl)morpholine] and poly(N,Ndimethylacrylamide) (Putnam and Kopeček 1995, Yang and Kopeček 2014). Among them, water-soluble polymer carriers based on HPMA copolymers and their drug conjugates have been substantially studied because of their excellent properties in vitro and in vivo. The first synthesis and polymerization of HPMA was published in early 1970s (Kopeček and Bažilová 1973). HPMA polymers and copolymers (P(HPMA)) have been used because of their suitable biological properties and biocompability for (Rihova and Kovar 2010) for their potential utilization in various fields of medicine. Watersoluble P(HPMA) compounds containing functional groups for the attachment of biologically active agents, such as drugs, enzymes, and hormones, were designed to form polymer conjugates and to serve as macromolecular drug carriers (Kopeček and Kopečková 2010). The versatility of P(HPMA) also enables the synthesis of these conjugates. The drug-polymer conjugates can be prepared either by the copolymerization of the HPMA monomer with a polymerizable derivative of a drug or by the attachment of the drug to HPMA copolymer precursors. Alternatively, P(HPMA) can be synthesized by the polymerization of activated methacrylate precursors with subsequent post-polymerization aminolysis of the active ester by 1-amino-propan-2-ol. Helmut Ringsdorf and colleagues developed this synthetic strategy in the early 1970s using hydrophobic reactive ester polymers as the precursor. With a postpolymerization modification (Kakuchi and Theato 2012), these polymers could be made water-soluble by a selective reaction with polar amines, while hydrophobic 
drugs could be attached to the polymers during this process in parallel (Batz et al. 1972). Another and more recent example is the synthesis of pentafluorophenyl methacrylate precursor polymers, followed by their conversion into P(HPMA), as demonstrated first by (Barz et al. 2008) and later on by (Gibson et al. 2009). Various biologically active compounds have been conjugated to P(HPMA), including anticancer drugs, antimicrobial agents, immunomodulators, proteins and imaging agents.

\section{Grafted and branched carriers}

The therapeutic activity of polymer prodrug conjugates can be increased by several ways. One method is the "passive" targeting of conjugates to solid tumors due to EPR effect (Maeda and Matsumura 2011), based on different ability of accumulation of conjugates by malignant and healthy tissue. The HMW of polymer carriers prevents the fast elimination of the bound drug from the organism by renal filtration. Thus, this characteristic enables their prolonged blood circulation and increased tumor uptake. The extent that the polymer carriers passively accumulate in solid tumors primarily depends on their molecular weight (Seymour et al. 1995). However, this trend reverse at very high molecular weights because of the slower extravasation of polymer systems with very high molecular weights, like star-like P(HPMA) with a $\mathrm{M}_{\mathrm{w}}$ of approximately $1,000,000 \mathrm{~g} / \mathrm{mol}$ (Etrych et al. 2011). Ideally, polymer drug carriers should be eliminated from the body after the drugs are delivered and released. Nevertheless, while the molecular weight of polymer carriers with biodegradable backbones is not limited. Polymers with non-degradable backbone of a molecular weight under a certain limit, approximately $\mathrm{M}_{\mathrm{w}}=50,000 \mathrm{~g} / \mathrm{mol}$ is the limit for vinylic copolymers, could be used for the synthesis of HMW polymers. Hence, HMW polymer drug carriers with a significant EPR effect need to contain biodegradable linkages between single, non-degradable polymer chains with an $M_{w}$ below the limit of renal filtration to increase passive targeting and allow for the following elimination of the carrier fragments from the body (Fig. 2 for the proposed schematic structures). In addition, HMW supramolecular structures, such as micelles formed by the self-assembly of amphiphilic copolymers with a molecular weight above the limit of renal threshold, were proposed. In this case, polymer carriers should be removed as unimers by glomerular filtration. In the following text, we will focus on the carriers, especially HMW P(HPMA), containing stimuli-responsive spacers that enable the degradation of HMW structures in the intratumoral or even intracellular environment through processes such as reduction or enzymolytic or $\mathrm{pH}$-sensitive hydrolysis.

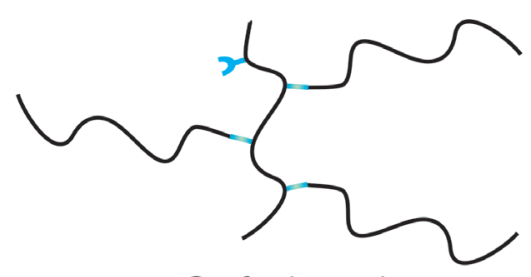

Grafted copolymer

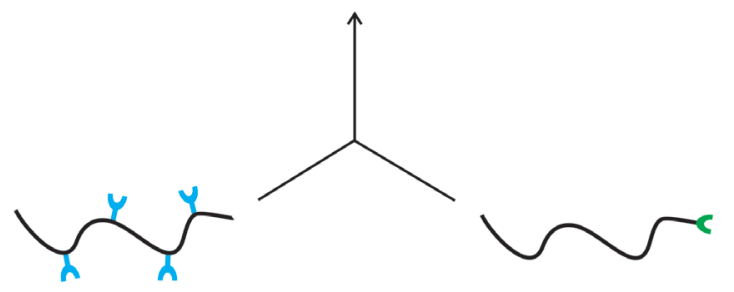

Multivalent copolymer

Semitelechelic copolymer

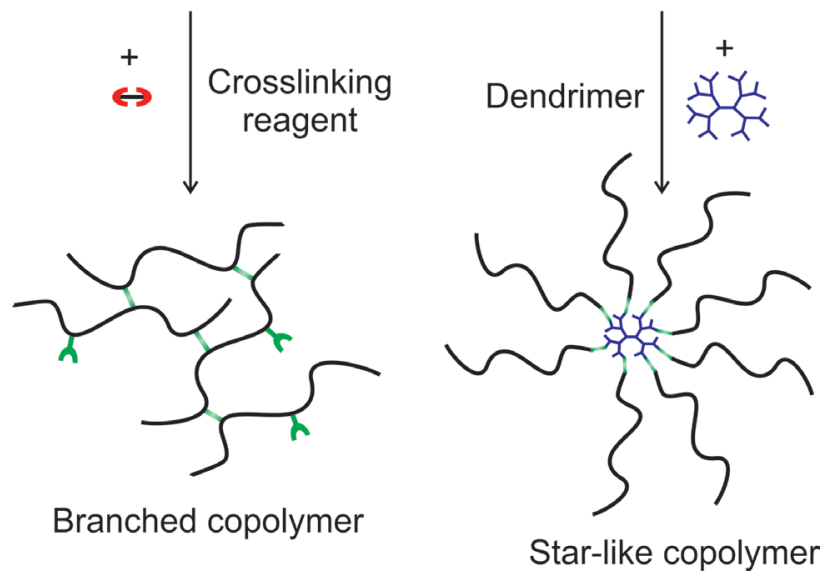

Fig. 2. Schematic description of the synthesis of HMW polymer carriers suitable for passively targeted prodrug systems.

The first proposed HMW structures were branched copolymers containing tetrapeptide GFLG spacers between linear P(HPMA) designed for enzymolysis by lysosomal enzymes in tumor cells (Dvořák et al. 1999, Etrych et al. 2001). They were prepared by copolymerization with the addition of the cross-linking agent N2,N5-bis(N-methacryloylglycyl-DLphenylalanylleucyl) ornithine, resulting in the formation of copolymers with a $\mathrm{M}_{\mathrm{w}}$ from 160,000 to $1,200,000 \mathrm{~g} / \mathrm{mol}$ (Dvorák et al. 1999). Here, the carrier was used for the attachment of the anticancer drug doxorubicin (Dox) with an enzymatically degradable GFLG spacer. Another branched polymer carrier bearing 
the hydrazide groups necessary for the attachment of Dox by a $\mathrm{pH}$-sensitive hydrazone bond was formed by the post-polymerization cross-linking of P(HPMA) bearing4-nitrophenyl glycyl-DL-phenylalanylleucylglycinate spacers that were distributed along the polymer chain by ethylenediamine, followed by hydrazinolysis of the remaining 4-nitrophenoxy (ONp) groups (Etrych et al. 2001). In both cases, the enzymatic degradation of the HMW structure was verified in vitro by incubation in a buffer in the presence of lysosomal enzyme cathepsin B. The prolonged blood circulation and tumor accumulation of Dox and an increase of therapeutic activity were observed in vivo. Nevertheless, the wide dispersity $(\mathrm{D}=3-7)$ and poor reproducibility of the synthesis limited the further development of branched carriers. More advanced graft polymer carriers were prepared by grafting semitelechelic $\mathrm{P}(\mathrm{HPMA})$ to multivalent $\mathrm{P}(\mathrm{HPMA})$ with spacers susceptible to enzymatic (GFLG oligopeptide) or reductive (S-S bond) degradation (Fig. 3 for the schematic synthesis) (Etrych et al. 2008). Semitelechelic P(HPMA)-containing Nhydroxy-succinimide (NHS) or thiazolidine-2-thione (TT) were grafted onto copolymers bearing GFLG spacers terminated by hydrazide or primary amino groups distributed randomly along the polymer chain. Alternatively, a semitelechelic P(HPMA)-containing pyridyldisulfanyl end-chain group was attached onto the copolymer using thiol groups formed by the thiolation of polymer-bound amine groups by 2 -iminothiolane. The prolonged blood circulation and enhanced tumor uptake of polymer conjugates with Dox bound through pH-sensitive hydrazone bond caused excellent anti-tumor activity. Nevertheless, the dispersity of the molecular weight significantly increased to $Đ=2.5-3$, while the dispersity of the polymer precursors was approximately 1.9. The molecular weight of these copolymers was approximately 90,000-120,000 g/mol.

As mentioned above, the poor reproducibility and the high dispersity of branched or grafted drug conjugates are their main drawbacks and limitations for the future development of these systems. Additionally, the molecular weights of the synthesized branched and grafted conjugate were the lowest among the compared HMW DDS. They were 2-3 times higher compared to the linear conjugate, and this increase of $M_{w}$ is not sufficient for maximal drug accumulation in solid tumors in comparison with star-like drug conjugates.

\section{Biodegradable graft PHPMA polymer conjugates with doxorubicin}

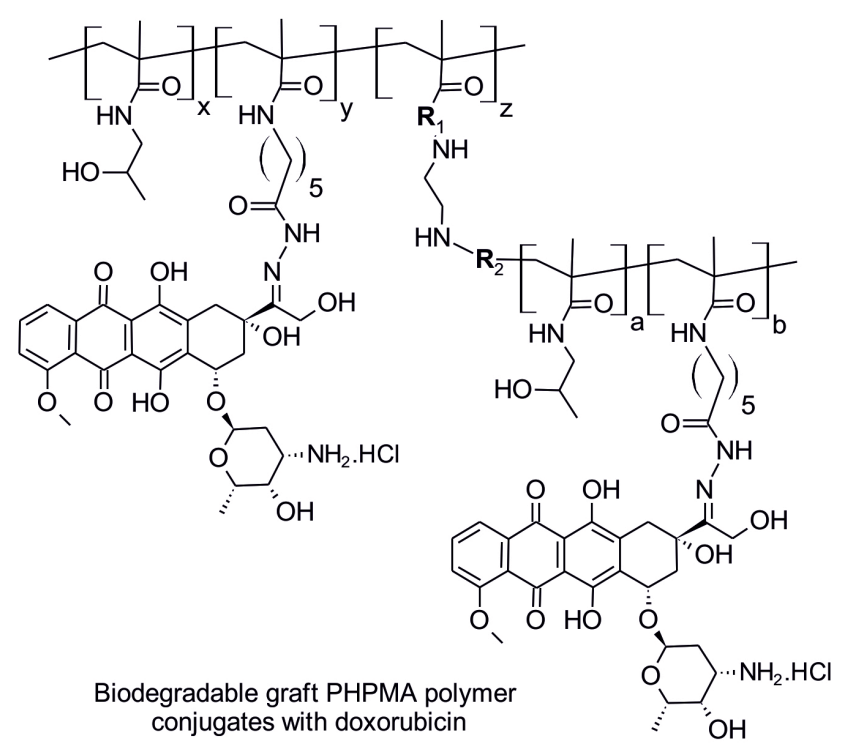

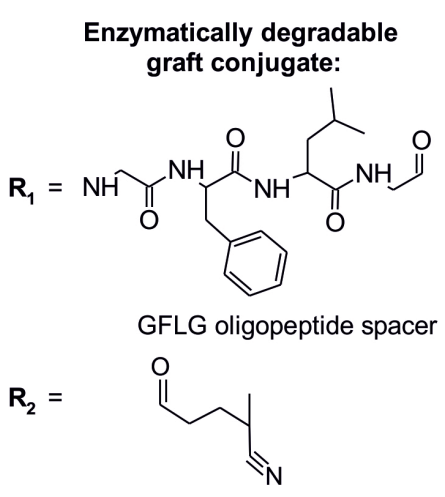

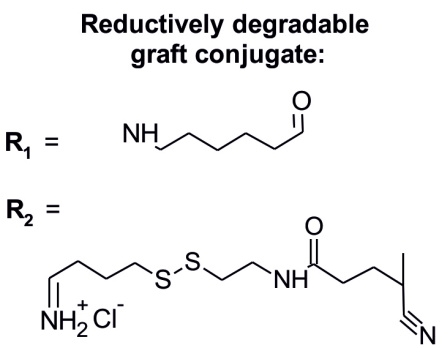

Fig. 3. Scheme of the HMW enzymatically or reductively degradable graft $\mathrm{P}(\mathrm{HPMA})$ conjugates with Dox bound by a pH-sensitive hydrazone bond.

\section{Multi-block carriers}

In addition to branched and grafted polymer systems, the use of linear HMW multi-block copolymers, in which telechelic or heterotelechelic linear polymers or copolymers are bound via biodegradable spacers, has been 
described. The multi-block copolymers were formed by polycondensation or polyaddition reactions. Both require very high functionality of polymer chain end-groups.

With the development of controlled radical polymerization techniques, various HPMA-based telechelic or heterotelechelic polymers or copolymers with a narrow distribution of molecular weights can be prepared by RAFT polymerization. Biodegradable multi-block P(HPMA) carriers containing enzymatically degradable linkers (GFLG tetrapeptide) were prepared using polyaddition reactions and thiol-ene or azide-alkyne click reactions (Luo et al. 2011, Pan et al. 2011, Yang et al. 2011). A bifunctional RAFT agent containing a GFLG tetrapeptide spacer was used for the preparation of telechelic P(HPMA) copolymers using RAFT polymerization initiated by $2,2^{\prime}$-azobis-(isobutyronitrile) (AIBN). After the removal of the terminal dithiobenzoate groups, free thiol groups were used in a polyaddition with bis-maleimide, forming a multi-blocked copolymer with an enzymatically degradable HMW backbone (Pan et al. 2011). Alternatively, a monofunctional RAFT agent containing a GFLG tetrapeptide spacer terminated by the propargyl group was used for the synthesis of a copolymer bearing an alkyne end-chain group. Because of the postpolymerization reaction with a diazido azoinitiator, the heterotelechelic P(HPMA) contained both $\alpha$-end alkyne and $\omega$-end azide groups. The multi-block copolymer was prepared by copper-catalyzed polyaddition (Fig. 4 for schematic synthesis) (Yang et al. 2011). Another bifunctional RAFT agent containing two propargyl groups was used for the synthesis of telechelic P(HPMA) copolymers by RAFT polymerization initiated by AIBN. The multi-block copolymer was formed by the coppercatalyzed polyaddition of the mentioned $\alpha, \omega$-dialkyne P(HPMA) and a diazido GFLG tetrapeptide linker (Luo et al. 2011). The dispersity of the multi-block P(HPMA) was wide because of the character of the polyaddition reactions, although the precursor's dispersity was quite low. Thus, the multi-block copolymers were fractionated to obtain HMW copolymers with a narrow dispersity. The HPMAbased multi-block copolymers were used as carriers of Dox, Ptx and gemcitabine bound via GFLG tetrapeptide spacer. Their properties, including their enhanced anticancer activity, were described in detail (Kopeček 2013, Yang and Kopeček 2014).

The quite complicated syntheses of the multiblock carriers mentioned above, together with the necessary fractionation of the product at the end of the synthesis, are the main drawbacks of these systems. The multi-block conjugates showed superior accumulation in solid tumors, which is in contrast to linear conjugates, but their accumulation is still lower than micellar or star-like carriers. The degradation of this multi-block conjugate with an enzymatically degradable linker was slow, most likely due to steric hindrance.

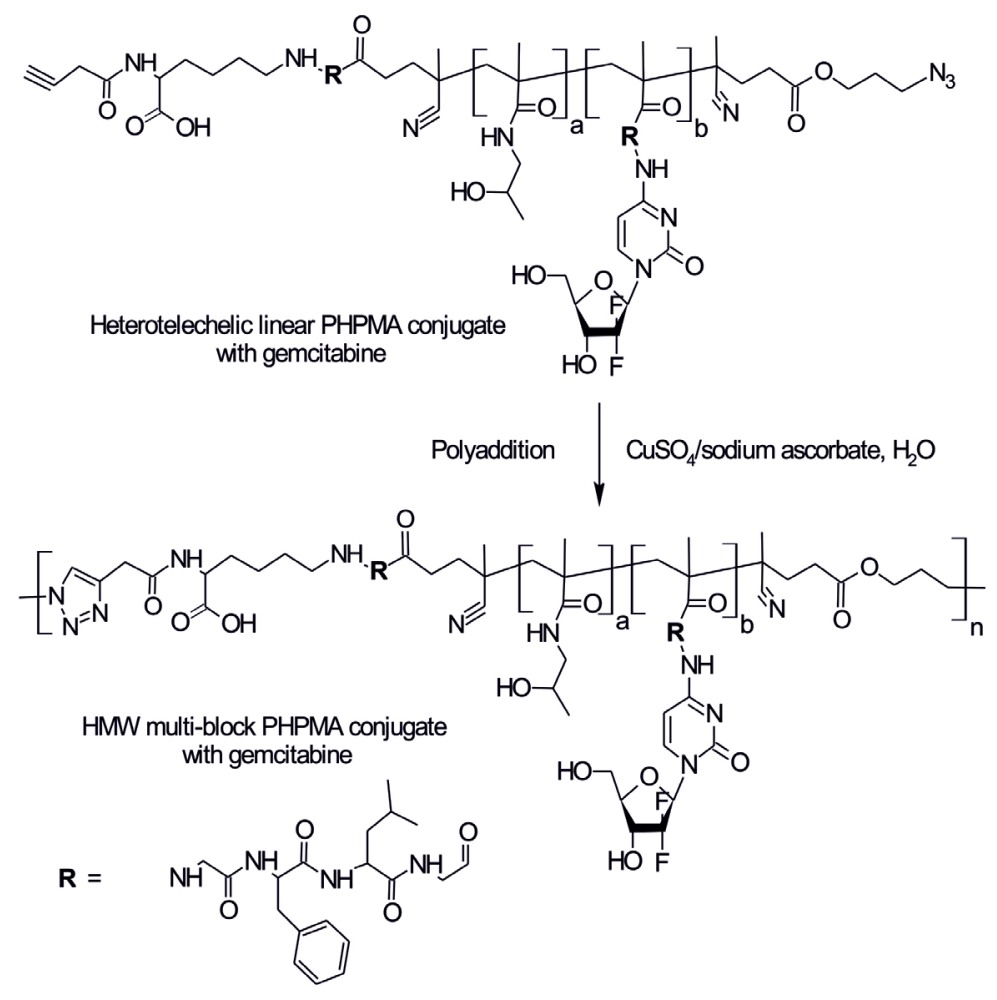

Fig. 4. Schematic sketch of the multiblock copolymer and an example of the synthesis of HMW enzymatically degradable multi-block P(HPMA) conjugates with gemcitabine bound through an enzymatically degradable GFLG spacer. 


\section{Micelles forming carriers}

Advances in the synthesis of amphiphilic block copolymers with a narrow molecular weight distribution and polymer blocks with a well-defined structure have facilitated the preparation of micellar drug carrier systems with diameters of 10-100 nm using the self-assembly of the copolymers in aqueous solution. The hydrophobic blocks form the core of the micelles and are surrounded by a hydrophilic polymer shell that stabilizes the micelles in aqueous solutions. The micelles are formed if the concentration of the copolymers exceeds the critical micelle concentration (CMC) and is in equilibrium with the unimers. The $\mathrm{CMC}$ depends on the temperature, $\mathrm{pH}$, and ionic strength of the solution. Polymeric micellebased delivery systems can be divided into two classes, depending on the method of drug loading: i) the drug is loaded in the micelle's hydrophobic core via noncovalent hydrophobic interactions, and this approach can be used to load any hydrophobic drug, regardless of its chemical structure or specific functional groups; or ii) the drug is conjugated with an amphiphilic polymer via a covalent bond. In following text, we will focus solely on P(HPMA)-based carriers with drugs covalently attached.

Random copolymers (with a size of $30 \mathrm{kDa}$ ) that self-assemble into micellar DDS capable of covalently binding to drugs via functional groups in the hydrophilic shell can be formed by preparing P(HPMA) derivatives from mixtures of co-monomers bearing hydrophobic dodecyl, oleic acid, or cholesterol moieties. Dox was conjugated to copolymers of this sort via a $\mathrm{pH}$-sensitive hydrazone bond. In aqueous media, the copolymers with a hydrophobic co-monomer content of $1.5-5 \mathrm{~mol} \%$ formed HMW supra-molecular structures with diameters of $13-37 \mathrm{~nm}$, depending on the type and relative abundance of the hydrophobic substituent (Chytil et al. 2008). Copolymers bearing Dox and hydrophobic cholesterol derivatives (cholesterol acylated with an oxoacid, cholest-4-en-3-one, or 5- $\alpha$-cholestanone), both bound by $\mathrm{pH}$-sensitive hydrazone bonds, were also synthesized. The hydrolysis of these hydrazone bonds in the mildly acidic environment of tumor cells resulted in drug release and the dissociation of the micelle supramolecular structure into unimers. The drug release profiles from these systems were similar to those for the related soluble P(HPMA) conjugates. EL4 T-cell lymphoma-bearing mice treated with these conjugates showed increased long-term survival and were fully cured at lower doses than were required to achieve comparable results with linear HPMA-based soluble systems. Dox was released in the first stage, whereas the highmolecular-weight supra-molecular polymer carrier disintegrated very slowly, forming relatively short polymer fragments those were small enough to be eliminated from the organism by glomerular filtration (Chytil et al. 2012).

One of the main advantages of this system is its long-term stability. It can be stored as a lyophilized powder, and the supra-molecular structure is reconstituted just before the application by the simple dissolution of the powder in physiological solution. The accumulation of these conjugates in solid tumors is comparable to starshaped conjugates due to the similar hydrodynamic radii of both systems. The drug release rate was not affected by the supra-molecular structure and was the same as for the linear conjugate if a hydrazone linker was used for drug attachment.

\section{Star-shaped HMW nanocarriers}

Another approach to the preparation of biodegradable HMW polymer carriers is related to starshaped dendrimer-derived polymer structures. In addition to the PEG copolymers mentioned above, several HPMAbased star-like copolymers and their drug conjugates were also prepared, and their properties were studied. The first star-like copolymers were formed by grafting polyaminoamide (PAMAM) dendrimers using semitelechelic HPMA-based copolymers terminated by NHS esters (Wang et al. 2000). Their $\mathrm{M}_{\mathrm{w}}$ varied from 20,000 to 200,000 approximately according to the used dendrimer generation (G2-G4 containing 16-64 surface amino groups, resp.). Dox was bound through a GFLG tetrapeptide spacer to the polymer precursor with the highest molecular weight. The drawback of the star-like carrier was the absence of biodegradable linkages between the dendrimer core and the polymer arms. The star-like carrier system was further improved using enzymatically (GFLG tetrapeptide) or reductively (S-S bond) degradable linkers (Etrych et al. 2011a). While the previous semitelechelic polymer precursor $\left(\mathrm{M}_{\mathrm{w}}=5,400 \mathrm{~g} / \mathrm{mol}\right)$ used by Wang et al. (2000) was prepared by radical chain-transfer polymerization, providing only short polymers, the use of functionalized azo-initiators derived from 4,4'-azobis(4-cyanovaleric acid) (ACVA) by Etrych et al. (2011a) afforded polymer precursors with a $\mathrm{M}_{\mathrm{w}}$ of approximately $25,000 \mathrm{~g} / \mathrm{mol}$ or 
higher (for an example of the synthesis of star-like P(HPMA), Figure 5 for the schematic synthesis).

The star polymer precursors were prepared by grafting the reactive semitelechelic HPMA copolymer precursors onto $2^{\text {nd }}$ or $3^{\text {rd }}$ generation PAMAM dendrimers containing 16 or 32 terminal amino groups and a diaminobutane or a diaminohexane core. A non-degradable star carrier containing Boc-protected hydrazide groups was prepared by the aminolysis of the TT end groups of the HPMA copolymer with amino groups of the PAMAM dendrimer in methanol. The biodegradable star polymer was prepared by the reaction of the carboxyl end group of the GFLG-OH terminal sequence of the linear polymer with the amino groups of the PAMAM dendrimer in DMF using the carbodiimide coupling method. In both cases, the polymer-modified dendrimer was isolated by precipitation in ethyl acetate (Etrych et al. 2011a, Etrych et al. 2015). Another biodegradable star-like copolymer with disulfide bonds was prepared as follows. The terminal TT groups of the P(HPMA) precursor were modified with 2-amino-ethylpyridyldisulfide, followed by reduction with dithiothreitol, which create thiol end groups on P(HPMA). Simultaneously, the primary amino groups of the PAMAM dendrimer were transformed into 2-pyridyldisulfanyl groups and then coupled to a P(HPMA) precursor with thiol end groups. Thus, the reductively degradable star-like P(HPMA) carrier was created. For more details, see Figure 5 (Etrych et al. 2011a).

Thus, the molecular weight of star-like copolymers varied from 50,000 to $1,000,000 \mathrm{~g} / \mathrm{mol}$, according to the dendrimer generation used and the molar ratio between the reactive end groups of polymer precursors and the dendrimer. Additionally, a significant increase in the dispersity (usually about $\mathrm{D}=1.6-2.1$ ) was not observed. Moreover, the use of polymer precursors prepared by RAFT polymerization enabled the synthesis of star-like copolymers with a very low dispersity (Chytil et al. 2015). Because of the low dispersity, any further fractionation was not necessary. Nevertheless, approximately $10-15 \%$ of unbound linear polymer precursor always remained in the samples but did not substantially influence the in vivo anticancer activity of their conjugates with Dox.

\section{Reductively degradable star-like PHPMA-Dox conjugate with drug bound}

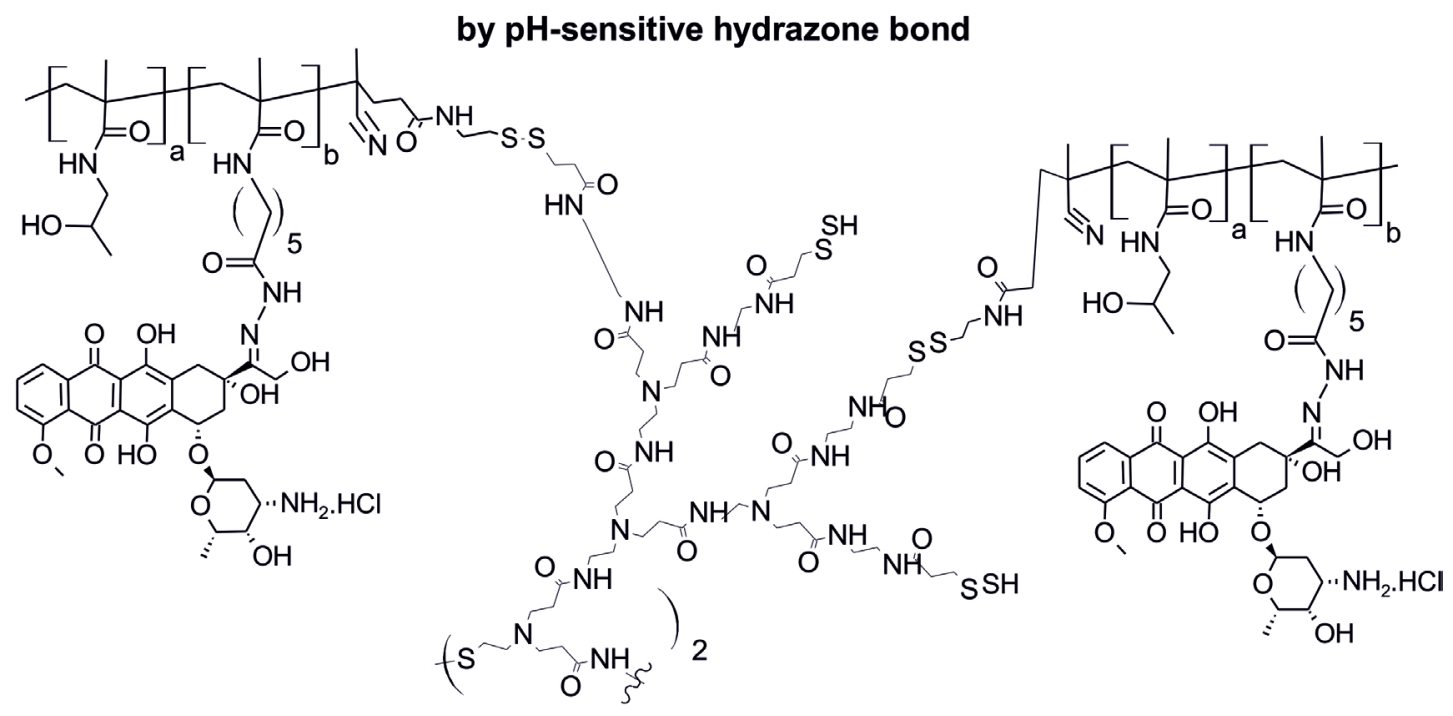

Fig. 5. Scheme of the synthesis of the HMW reductively degradable star-like $\mathrm{P}(\mathrm{HPMA})$ conjugate with Dox bound by a pH-sensitive hydrazone bond.

The in vivo evaluation of star-like conjugates with Dox showed prolonged blood circulation, enhanced tumor accumulation (Fig. 6) and excellent anti-tumor activity, even at very low doses against various syngeneic tumor models (Etrych et al. 2011a, Etrych et al. 2011c.) The crucial influence of the molecular weight of the carrier was demonstrated, showing its impact on the circulation time, accumulation in tumors (Fig. 6), tumorto-blood and tumor-to-muscle ratio and elimination via urine (Etrych et al. 2012).

The enhanced therapeutic efficacy of star conjugates bearing other drugs than Dox, like pirarubicin (Nakamura et al. 2015), docetaxel (Etrych et al. 2015), was also exhibited in the treatment of various syngeneic 
and xenograft tumors. The preclinical in vivo characterization of polymer-drug conjugates is important for understanding the impact of structural design onto their distribution and elimination from the body. Thus, the dual-labeled linear or HMW star-like P(HPMA) conjugates with fluorescent dyes were synthesized, and their in vivo fate was studied by non-invasive multispectral optical imaging (Hoffmann et al. 2012). The combination of near infrared (DY-782) and far red (DY-676) fluorescent dyes provided information about the distribution from deep tissues, such as the liver, spleen and kidneys. The far red dye was coupled via a degradable $\mathrm{pH}$-sensitive hydrazone bond (modeling drug), whereas the near infrared dye labelled the polymer backbone via a non-cleavable hydrazide bond (following the fate of the carrier).

Various P(HPMA) carriers with Dox differed in their molecular weights, dispersity and molecular architecture (flexible linear vs. less flexible star-like structures) were compared in vivo; their biological properties, namely blood clearance, renal elimination, tumor and liver accumulation and survival of mice bearing EL 4 T-cell lymphoma were assessed (Etrych et al. 2012).

Polymer nanomedicines above a certain size cannot achieve effective extravasation or tumor accumulation. For HPMA polymers, this size limit appears to be approximately $50 \mathrm{~nm}$, which corresponds to an $\mathrm{M}_{\mathrm{w}}$ of approximately $600 \mathrm{kDa}$ (Etrych et al. 2012). Conjugates with $\mathrm{M}_{\mathrm{w}}$ values above $1,000 \mathrm{kDa}(100 \mathrm{~nm})$ exhibited markedly reduced accumulation in tumors. It was shown that the pharmacokinetics of star-like polymer conjugates is more advantageous, resulting in the enhanced accumulation of model drugs in tumor tissue. Nevertheless, the counterweight of high efficacy is a rather narrow therapeutic window (Tomalova et al. 2016) in comparison to their polymer analogues with linear structures and molecular weights below the renal filtration limit.

The star-shaped drug conjugates with a molecular weight of $150-300 \mathrm{kDa}$ showed superior accumulation in solid tumors over all the mentioned architectures of P(HPMA) carriers, including the linear, diblock or grafted carriers. The proper design of the starshaped carrier and its easy synthesis, together with its superior accumulation of the drug in tumor tissues, overwhelms the main disadvantage of this system - the rather narrow therapeutic window.

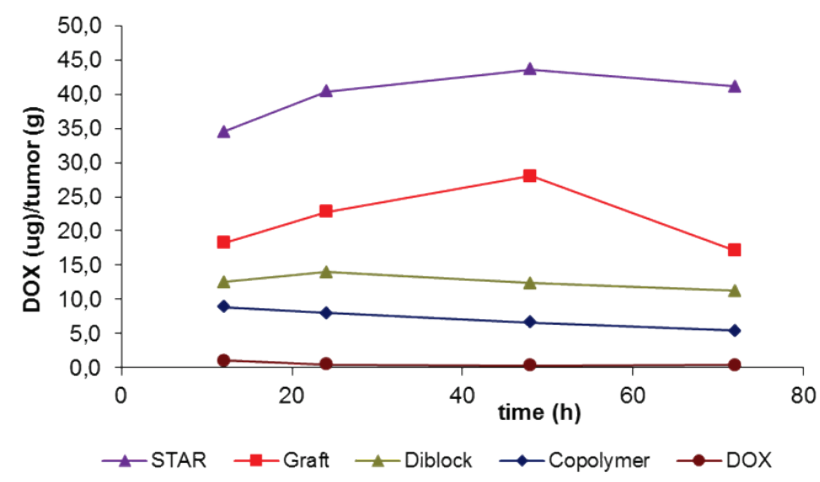

Fig. 6. Tumor drug accumulation of polymer drug carriers with different architectures. All conjugates were administered day 8 after inoculation of tumor cells at a dose of $15 \mathrm{mg} \mathrm{Dox} \mathrm{eq/kg.} \mathrm{All}$ conjugates were $\mathrm{P}(\mathrm{HPMA})$-based copolymers with $\mathrm{pH}$-sensitive bound Dox. Violet line - star-like conjugate, red line - grafted conjugate, green line - diblock copolymer Dox conjugate, blue line - linear copolymer conjugate, brown line - free drug.

\section{Conclusions}

Tumor-specific delivery based on the EPR effect of various DDS, together with that based on HPMA copolymers, is the key parameter for obtaining suitable candidates that are primarily applicable in the treatment of vascularized solid tumors. Indeed, the size of the polymer coil in solution controls the rate of polymer elimination by glomerular filtration and contemporarily accumulation within solid tumors. Branched, grafted, micellar, star-like or multi-block P(HPMA) conjugates or multi-block PEG conjugates showed prolonged blood circulation and enhanced tumor accumulation of the drug, displaying their superior anti-tumor activity against various solid tumor models. The potential and capability of HMW conjugates should be further studied in detail.

\section{Conflict of Interest}

There is no conflict of interest.

\section{Acknowledgements}

This work was supported by the Ministry of Education, Youth and Sports of CR within the National Sustainability Program I, Project POLYMAT LO1507.

\section{References}

ASGEIRSSON D, AXELSSON J, RIPPE C, RIPPE B: Similarity of permeabilities for Ficoll, pullulan, charge-modified albumin and native albumin across the rat peritoneal membrane. Acta Physiol (Oxf) 196: 427-433, 2009. 
ASGEIRSSON D, VENTUROLI D, FRIES E, RIPPE B, RIPPE C: Glomerular sieving of three neutral polysaccharides, polyethylene oxide and bikunin in rat. Effects of molecular size and conformation. Acta Physiol (Oxf) 191: 237-246, 2007.

BARZ M, TARANTOLA M, FISCHER K, SCHMIDT M, LUXENHOFER R, JANSHOFF A, THEATO P, ZENTEL R: From defined reactive diblock copolymers to functional HPMA-based self-assembled nanoaggregates. Biomacromolecules 9: 3114-3118, 2008.

BATZ HG, FRANZMAN G, RINGSDOR H: Model reactions for synthesis of pharmacologically active polymers by way of monomeric and polymeric reactive esters. Angew Chem Int Ed 11: 1103-1104, 1972.

CHYTIL P, ETRYCH T, KOŇÁK Č, ŠÍROVÁ M, MRKVAN T, BOUČEK J, ŘÍHOVÁ B, ULBRICH K: New HPMA copolymer-based drug carriers with covalently bound hydrophobic substituents for solid tumour targeting. $J$ Control Release 127: 121-130, 2008.

CHYTIL P, ETRYCH T, KOSTKA L, ULBRICH K: Hydrolytically degradable polymer micelles for anticancer drug delivery to solid tumors. Macromol Chem Phys 213: 858-867, 2012.

CHYTIL P, KOZIOLOVA E, JANOUSKOVA O, KOSTKA L, ULBRICH K, ETRYCH T: Synthesis and properties of star HPMA copolymer nanocarriers synthesised by raft polymerisation designed for selective anticancer drug delivery and imaging. Macromol Biosci 15: 839-850, 2015.

DEEN WM, LAZZARA MJ, MYERS BD: Structural determinants of glomerular permeability. Am J Physiol Renal Physiol 281: F579-F596, 2001.

DUNCAN R: Polymer conjugates as anticancer nanomedicines. Nat Rev Cancer 6: 688-701, 2006.

DUNCAN R, VICENT MJ: Polymer therapeutics-prospects for 21st century: The end of the beginning. Adv Drug Deliv Rev 65: 60-70, 2013.

DVOŘÁK M, KOPEČKOVÁ P, KOPEČEK J: High-molecular weight HPMA copolymer-adriamycin conjugates. J Control Release 60: 321-332, 1999.

ETRYCH T, CHYTIL P, MRKVAN T, ŠÍROVÁ M, ŘIIHOVÁ B, ULBRICH K: Conjugates of doxorubicin with graft HPMA copolymers for passive tumor targeting. J Control Release 132: 184-192, 2008.

ETRYCH T, JELÍNKOVÁ M, ŘÍHOVÁ B, ULBRICH K: New HPMA copolymers containing doxorubicin bound via $\mathrm{pH}$-sensitive linkage: synthesis and preliminary in vitro and in vivo biological properties. $J$ Control Release 73: 89-102, 2001.

ETRYCH T, KOVÁŘ L, STROHALM J, CHYTIL P, ŘÍHOVÁ B, ULBRICH K: Biodegradable star HPMA polymerdrug conjugates: Biodegradability, distribution and anti-tumor efficacy. J Control Release 154: 241-248, 2011a.

ETRYCH T, STROHALM J, CHYTIL P, ČERNOCH P, STAROVOYTOVA L, PECHAR M, ULBRICH K: Biodegradable star HPMA polymer conjugates of doxorubicin for passive tumor targeting. Eur J Pharm Sci 42: 527-539, 2011b.

ETRYCH T, STROHALM J, CHYTIL P, RIHOVA B, ULBRICH K: Novel star HPMA-based polymer conjugates for passive targeting to solid tumors. J Drug Target 19: 874-889, 2011c.

ETRYCH T, STROHALM J, SIROVA M, TOMALOVA B, ROSSMANN P, RIHOVA B, ULBRICH K, KOVAR M: High-molecular weight star conjugates containing docetaxel with high anti-tumor activity and low systemic toxicity in vivo. Polym Chem 6: 160-170, 2015.

ETRYCH T, ŠUBR V, STROHALM J, ŠÍROVÁ M, ŘÍHOVÁ B, ULBRICH K: HPMA copolymer-doxorubicin conjugates: The effects of molecular weight and architecture on biodistribution and in vivo activity. $J$ Control Release 164: 346-354, 2012.

FOX ME, SZOKA FC, FRÉCHET JMJ: Soluble polymer carriers for the treatment of cancer: The importance of molecular architecture. Acc Chem Res 42: 1141-1151, 2009.

GIBSON MI, FROHLICH E, KLOK HA: Postpolymerization modification of poly(pentafluorophenyl methacrylate): Synthesis of a diverse water-soluble polymer library. J Polym Sci Pol Chem 47: 4332-4345, 2009.

HOFFMANN S, VYSTRCILOVA L, ULBRICH K, ETRYCH T, CAYSA H, MUELLER T, MADER K: Dual fluorescent HPMA copolymers for passive tumor targeting with $\mathrm{pH}$-sensitive drug release: Synthesis and characterization of distribution and tumor accumulation in mice by noninvasive multispectral optical imaging. Biomacromolecules 13: 652-663, 2012. 
KAKUCHI R, THEATO P: Post-polymerization modifications via active esters. In: Functional Polymers by PostPolymerization Modification: Concepts, Guidelines, and Applications. THEATO P, KLOK H-A (eds), WileyVCH Verlag GmbH \& Co. KGaA, Weinheim, 2012, pp 45-64.

KOPEČEK J: Soluble polymers in medicine. In: Systemic aspects of biocompatibility, vol. II. WILLIAMS DF (ed.), CRC press, 1981, pp 159-180.

KOPEČEK J: Preface: Biomaterials and drug delivery: Past, present, and future. Mol Pharmaceut 7: 922-925, 2010.

KOPEČEK J: Polymer-drug conjugates: Origins, progress to date and future directions. Adv Drug Deliver Rev 65: 4959, 2013.

KOPEČEK J, BAŽILOVÁ H: Poly[N-(2-hydroxypropyl)methacrylamide]-I. Radical polymerization and copolymerization. Eur Polym J 9: 7-14, 1973.

KOPEČEK J, KOPEČKOVÁ P: HPMA copolymers: Origins, early developments, present, and future. Adv Drug Deliver Rev 62: 122-149, 2010.

LAMMERS T, KÜHNLEIN R, KISSEL M, SUBR V, ETRYCH T, POLA R, PECHAR M, ULBRICH K, STORM G, HUBER P, PESCHKE P: Effect of physicochemical modification on the biodistribution and tumor accumulation of HPMA copolymers. J Control Release 110: 103-118, 2005.

LI C: Poly(L-glutamic acid) - anticancer drug conjugates. Adv Drug Deliv Rev 54: 695-713, 2002.

LUO K, YANG J, KOPEČKOVÁ P, KOPEČEK JI: Biodegradable multiblock poly[n-(2-hydroxypropyl)methacrylamide] via reversible addition-fragmentation chain transfer polymerization and click chemistry. Macromolecules 44: 2481-2488, 2011.

MAEDA H, GREISH K, FANG J: The EPR effect and polymeric drugs: A paradigm shift for cancer chemotherapy in the 21st century. Adv Polym Sci 193: 103-121, 2006.

MAEDA H, MATSUMURA Y: EPR effect based drug design and clinical outlook for enhanced cancer chemotherapy. Adv Drug Deliv Rev 63: 129-130, 2011.

MATSUMURA Y, MAEDA H: A new concept for macromolecular therapeutics in cancer chemotherapy: Mechanism of tumoritropic accumulation of proteins and the antitumor agent smancs. Cancer Res 46: 6387-6392, 1986.

NAKAMURA H, KOZIOLOVA E, ETRYCH T, CHYTIL P, FANG J, ULBRICH K, MAEDA H: Comparison between linear and star-like HPMA conjugated pirarubicin (THP) in pharmacokinetics and antitumor activity in tumor bearing mice. Eur J Pharm Biopharm 90: 90-96, 2015.

NASONGKIA N, CHEN B, MACARAEG N, FOX ME, FRÉCHET JMJ, SZOKA FC: Dependence of pharmacokinetics and biodistribution on polymer architecture: Effect of cyclic versus linear polymers. $J \mathrm{Am}$ Chem Soc 131: 3842-3843, 2009.

PAN HZ, YANG JY, KOPECKOVA P, KOPECEK J: Backbone degradable multiblock n-(2hydroxypropyl)methacrylamide copolymer conjugates via reversible addition-fragmentation chain transfer polymerization and thiol-ene coupling reaction. Biomacromolecules 12: 247-252, 2011.

PASUT G, SERGI M, VERONESE FM: Anti-cancer PEG-enzymes: 30 years old, but still a current approach. $A d v$ Drug Deliv Rev 60: 69-78, 2008.

PASUT G, VERONESE FM: PEG conjugates in clinical development or use as anticancer agents: An overview. $A d v$ Drug Deliv Rev 61: 1177-1188, 2009.

PECHAR M, BRAUNOVA A, ULBRICH K: Poly(ethylene glycol)-based polymer carrier of doxorubicin degradable by both enzymatic and chemical hydrolyses. Collect Czech Chem Commun 70: 327-338, 2005.

PUTNAM D, KOPEČEK J: Polymer conjugates with anticancer activity. Biopolymers 122: 55-123, 1995.

RENNKE HG, VENKATACHALAM MA: Glomerular permeability of macromolecules. Effect of molecular configuration on the fractional clearance of uncharged dextran and neutral horseradish peroxidase in the rat. J Clin Invest 63: 713-717, 1979.

RIHOVA B, KOVAR M: Immunogenicity and immunomodulatory properties of HPMA-based polymers. Adv Drug Deliver Rev 62: 184-191, 2010.

ŘÍHOVÁ B, KOVÁŘ L, KOVÁŘ M, HOVORKA O: Cytotoxicity and immunostimulation: double attack on cancer cells with polymeric therapeutics. Trends Biotechnol 27: 11-17, 2009.

Ř́lHOVÁ B, KOVÁŘ M: Immunogenicity and immunomodulatory properties of HPMA-based polymers. Adv Drug Deliver Rev 62: 184-191, 2010. 
SEYMOUR LW, MIYAMOTO Y, MAEDA H, BRERETON M, STROHALM J, ULBRICH K, DUNCAN R: Influence of molecular-weight on passive tumor accumulation of a soluble macromolecular drug carrier. Eur $J$ Cancer 31A: 766-770, 1995.

SCHACHT EH, VANSTEENKISTE S, SEYMOUR LW, KOSTELNIK RJ: Macromolecular carriers for drug targeting. In: The Practice of Medicinal Chemistry. KOSTELNIK RJ (ed.), Academic Press, New York, 1996, pp. 718-736.

TENCER J, FRICK IM, ÖQUIST BW, ALM P, RIPPE B: Size-selectivity of the glomerular barrier to high molecular weight proteins: Upper size limitations of shunt pathways. Kidney Int 53: 709-715, 1998.

TOMALOVA B, SIROVA M, ROSSMANN P, POLA R, STROHALM J, CHYTIL P, CERNY V, TOMALA J, KABESOVA M, RIHOVA B, ULBRICH K, ETRYCH T, KOVAR M: The structure-dependent toxicity, pharmacokinetics and anti-tumour activity of HPMA copolymer conjugates in the treatment of solid tumours and leukaemia. J Control Release 223: 1-10, 2016.

VENKATACHALAM MA, RENNKE HG: The structural and molecular basis of glomerular filtration. Circ Res 43: $337-347,1978$.

VIEGAS TX, BENTLEY MD, HARRIS JM, FANG Z, YOON K, DIZMAN B, WEIMER R, MERO A, PASUT G, VERONESE FM: Polyoxazoline: Chemistry, properties, and applications in drug delivery. Bioconjugate Chem 22: 976-986, 2011.

WANG D, KOPEČKOVÁ P, MINKO T, NANAYAKKARA V, KOPEČEK J: Synthesis of starlike $N$-(2hydroxypropyl)methacrylamide copolymers: Potential drug carriers. Biomacromolecules 1: 313-319, 2000.

YANG J, KOPEČEK J: Macromolecular therapeutics. J Control Release 190: 288-303, 2014.

YANG J, LUO K, PAN H, KOPECKOVA P, KOPECEK J: Synthesis of biodegradable multiblock copolymers by click coupling of RAFT-generated heterotelechelic polyHPMA conjugates. React Funct Polym 71: 294-302, 2011. 